\title{
Activity of $\mathrm{Cu}-\mathrm{Al}$-Oxo Extra-Framework Clusters for Selective Methane Oxidation on Cu-Exchanged Zeolites
}

Insu Lee, ${ }^{\dagger}$ Mal-Soon Lee, ${ }^{* \dagger}$ Lei Tao, Takaaki Ikuno, Rachit Khare, Andreas Jentys, Thomas Huthwelker, Camelia N. Borca, Aleksandr Kalinko, Oliver Y. Gutiérrez, Niri Govind, John L. Fulton, Jian Zhi Hu, Vassiliki-Alexandra Glezakou, Roger Rousseau, Maricruz Sanchez-Sanchez,* and Johannes A. Lercher*

Cite This: JACS Au 2021, 1, 1412-1421

Read Online

ACCESS |

山ll Metrics \& More

Article Recommendations

Supporting Information

ABSTRACT: $\mathrm{Cu}$-zeolites are able to directly convert methane to methanol via a three-step process using $\mathrm{O}_{2}$ as oxidant. Among the different zeolite topologies, $\mathrm{Cu}$-exchanged mordenite (MOR) shows the highest methanol yields, attributed to a preferential formation of active $\mathrm{Cu}-$ oxo species in its 8 -MR pores. The presence of extraframework or partially detached Al species entrained in the micropores of MOR leads to the formation of nearly homotopic redox active $\mathrm{Cu}-\mathrm{Al}$-oxo nanoclusters with the ability to activate $\mathrm{CH}_{4}$. Studies of the activity of these sites together with characterization by ${ }^{27} \mathrm{Al} \mathrm{NMR}$ and IR spectroscopy leads to the conclusion that the active species are located in the 8-MR side pockets of $\mathrm{MOR}$, and it consists of two $\mathrm{Cu}$ ions and one $\mathrm{Al}$ linked by

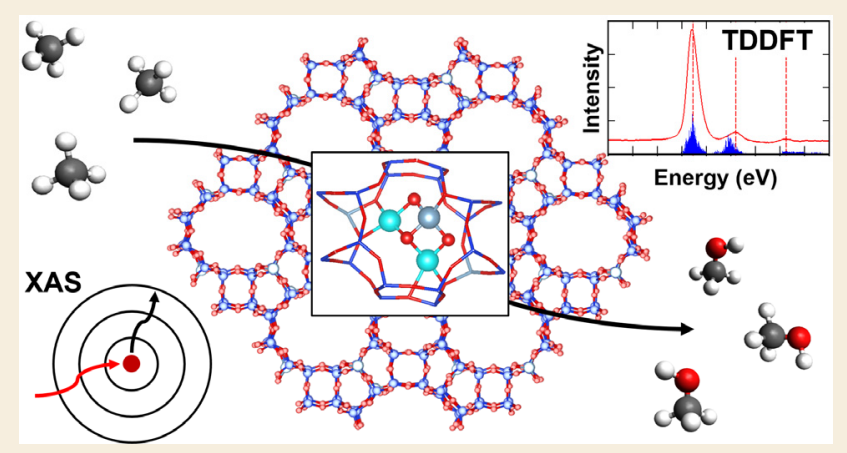
$\mathrm{O}$. This $\mathrm{Cu}-\mathrm{Al}$-oxo cluster shows an activity per $\mathrm{Cu}$ in methane oxidation significantly higher than of any previously reported active $\mathrm{Cu}$-oxo species. In order to determine unambiguously the structure of the active $\mathrm{Cu}-\mathrm{Al}$-oxo cluster, we combine experimental XANES of $\mathrm{Cu} \mathrm{K}$ - and L-edges, $\mathrm{Cu}$ K-edge HERFD-XANES, and $\mathrm{Cu}$ K-edge EXAFS with TDDFT and AIMD-assisted simulations. Our results provide evidence of a $\left[\mathrm{Cu}_{2} \mathrm{AlO}_{3}\right]^{2+}$ cluster exchanged on $\mathrm{MOR} \mathrm{Al}$ pairs that is able to oxidize up to two methane molecules per cluster at ambient pressure.

KEYWORDS: Methane oxidation, $\mathrm{Cu} \mathrm{L}_{3}$-edge XANES, HERFD, TDDFT, zeolite, AIMD

\section{INTRODUCTION}

Increased availability of light hydrocarbons from shale gas raised the interest in methane as feedstock for the petrochemical industry. ${ }^{1}$ Currently, methane is mainly converted via synthesis gas to methanol, higher alcohols, and a range of hydrocarbons. ${ }^{1,2}$ Despite the high maturity of these routes, a single-step transformation would have significant advantages, triggering substantial interest in the direct conversion of methane to methanol. ${ }^{2-5}$

Copper-exchanged zeolites have shown activity in the selective oxidation in repeatable single turnovers using $\mathrm{O}_{2}$ as oxidant. ${ }^{3,6,7}$ Grootheart et al. were the first to demonstrate this via a cyclic three-stage process, which is depicted schematically in Figure $1 .^{8}$ Among the variety of zeolite topologies, zeolite MOR, having straight 12-membered-ring (MR) channels and intersecting 8-MR side pockets, had the best utilization of copper. $^{3,6,9}$ Dimeric $^{10-15}$ and trimeric ${ }^{16-19} \mathrm{Cu}$-oxo clusters have been proposed to be the main active sites. $\mathrm{Al}$ pairs in the 8-MR side pockets of MOR favor the formation and stabilization of such active $\mathrm{Cu}$-oxo sites. ${ }^{17,18,20,21}$ It has been established that each $\mathrm{Cu}$-oxo cluster is able to oxidize one $\mathrm{CH}_{4}$ at ambient pressure and up to two $\mathrm{CH}_{4}$ at higher $\mathrm{CH}_{4}$ chemical potentials. ${ }^{22}$ of methane to methanol over $\mathrm{Cu}$-exchanged zeolites.
Received: May 5, 2021

Published: July 14, 2021

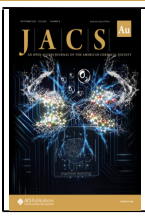


The fraction of $\mathrm{Cu}$ that can be stabilized as active $\mathrm{Cu}-$ oxo clusters in a zeolite depends on the concentration of $\mathrm{Al}$ in the zeolite lattice, its crystallographic position, the fraction of $\mathrm{Al} \mathrm{T}$ sites among its next nearest neighbors, and the presence of other cations in the zeolite. Optimized ion-exchange protocols and the absence of cocations leads to high concentrations of active $\mathrm{Cu}$-oxo sites. ${ }^{17,18}$

In the absence of other metal cations, Brønsted acidic zeolites undergo some dealumination, resulting in the formation of (partially detached) extra-framework $\mathrm{Al}$ (EFAl) species such as $\mathrm{Al}(\mathrm{OH})_{x}\left(\mathrm{Al}_{x} \mathrm{O}_{y}\right) .^{23-27}$ These EFAl species influence Brønsted acid site (BAS)-catalyzed reactions. ${ }^{28-32} \mathrm{~A}$ recent study by Dyballa et al. reported Cu-MOR materials with an increased activity in methane oxidation and associated it to the presence of higher concentrations of extra-framework aluminum. ${ }^{33}$ However, it is unknown how the EFAl influence active $\mathrm{Cu}$-oxo species.

In this work, we investigate the activity of methane oxidation to methanol by $\mathrm{Cu}$-oxo species in MOR in the presence of EFAl. We report on a series of Cu-MOR with nearly $2 \times$ higher productivity per $\mathrm{Cu}$ atom than so far established for the best $\mathrm{Cu}-\mathrm{MOR}$ materials (under 1 bar and stepwise mode). ${ }^{14,16,17}$ This drastic increase in activity points to an intrinsically different $\mathrm{Cu}-$ oxo species.

Using NMR and IR spectroscopy, we report evidence of the interaction of $\mathrm{Cu}$ with extra-framework $\mathrm{Al}$ species in these highly active $\mathrm{Cu}$-exchanged zeolites. To better understand the sites, the $\mathrm{Cu}-\mathrm{MOR}$ samples were studied by a combination of $\mathrm{X}$-ray absorption spectroscopies (XAS) and theory. Highenergy-resolution-fluorescence-detected (HERFD) and X-ray absorption near-edge structure (XANES) of the $\mathrm{Cu}$ K-edge were used to define the nature and local geometry of $\mathrm{Cu} .{ }^{34}$ The combination of structural and chemical information derived from these measurements together with EXAFS of the $\mathrm{Cu} \mathrm{K}$ - and $\mathrm{Al}$ K-edges of the $\mathrm{Cu}-\mathrm{MOR}$ materials and $\mathrm{Cu} \mathrm{L}$ edge XANES is used to characterize the oxidation state of $\mathrm{Cu}$ together with highly specific information about bonding of the oxo ligands. ${ }^{35}$ To complement and augment our experimental measurements, we have performed ground state spin-polarized density functional theory (DFT)-based ab initio molecular dynamics (AIMD) simulations and EXAFS and TDDFT-based XANES calculations. ${ }^{36}$

\section{RESULTS AND DISCUSSION}

\section{Activity of Cu-MOR Catalysts Prepared under Controlled Conditions}

We have measured the reactivity of two $\mathrm{Cu}-\mathrm{MOR}$ series, denoted as $\mathrm{Cu}-\mathrm{MOR}-\mathrm{A}$ and $\mathrm{Cu}-\mathrm{MOR}-\mathrm{B}$, in a typical threestage reaction comprising of (1) high temperature activation of $500{ }^{\circ} \mathrm{C}$ in $\mathrm{O}_{2},(2)$ exposure to methane at $200{ }^{\circ} \mathrm{C}$ and 1 bar, and (3) product desorption by steam treatment. In order to compare the relative reactivity of $\mathrm{Cu}-\mathrm{MOR}$ samples, we define the $\mathrm{Cu}$ efficiency $\left(\mathrm{Cu}_{\text {eff }}\right)$ as the molar ratio of all converted $\mathrm{CH}_{4}$ to the total amount of $\mathrm{Cu}$ present. Our previous reports agree well with those of other authors in reporting an upper limit of $\mathrm{Cu}_{\text {eff }}=0.35$ for $\mathrm{Cu}-\mathrm{MOR}$ materials at 1 bar. ${ }^{14,16,17,22,37}$ Only when the $\mathrm{CH}_{4}$ chemical potential was significantly increased (by increasing $\mathrm{P}_{\mathrm{CH} 4}$ to $40 \mathrm{bar}$, for instance) it was possible to achieve higher $\mathrm{Cu}_{\text {eff }}$ values, in the range of $0.45-$ $0.6^{14,22}$

Here, we report an unusually high $\mathrm{Cu}_{\text {eff }}$ for $\mathrm{Cu}$ exchanged on a zeolite (H-MOR-B) that contains extra-framework aluminum
(EFAl) at a different T-site position. For this highly active $\mathrm{Cu}$ MOR zeolite series, an average $\mathrm{Cu}_{\text {eff }}$ of 0.58 was obtained at 1 bar for $\mathrm{Cu}$ loadings up to $300 \mu \mathrm{mol} / \mathrm{g}$ (Figure 2). ${ }^{14,15,33}$

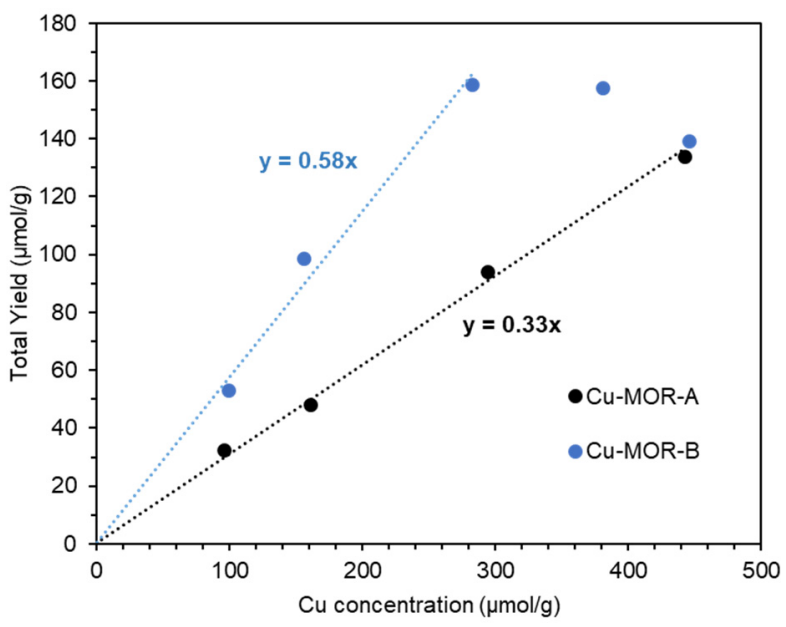

Figure 2. Yield of $\mathrm{CH}_{4}$ oxidation on the $\mathrm{Cu}-\mathrm{MOR}$ catalysts prepared from different parent $\mathrm{H}-\mathrm{MOR}$ samples with different $\mathrm{Cu}$ loading of $\mathrm{Cu}-\mathrm{MOR}-\mathrm{A}$ and $\mathrm{Cu}-\mathrm{MOR}-\mathrm{B}$ series. Numerical values of the $\mathrm{Cu}_{\text {eff }}$ are given as $y=\mathrm{Cu}_{\mathrm{eff}} x$ for Cu-MOR-A (black) and Cu-MOR-B (blue). Activity tests were repeated three times on each catalyst and averaged values are reported.

Selectivities to $\mathrm{MeOH}$ and its dehydration product dimethyl ether/DME) were in the range of 65 to $85 \%$ (see Supporting Information, Figure S1) and activity was fully restored by the oxidative treatment at least for seven consecutive catalytic cycles (Figure S2). We include here for comparison the $\mathrm{Cu}$ MOR-A series, showing consistently a $\mathrm{Cu}_{\text {eff }}$ of 0.33 and selectivities to $\mathrm{MeOH}+\mathrm{DME}$ between 65 and $80 \%$ (Figure $\mathrm{S} 1$ ). Our previous work on this material allows us to firmly attribute the activity to the oxidation of one molecule of $\mathrm{CH}_{4}$ by a $\left[\mathrm{Cu}_{3}(\mu-\mathrm{O})_{3}\right]^{2+}$ cluster. ${ }^{17}$ Characterization of these different $\mathrm{Cu}$-MOR samples is used to elucidate the origin of the high efficiency achieved for the new material.

\section{Characterization of Parent MOR-A and MOR-B Samples}

The distribution of $\mathrm{Al}$ in the zeolite framework is an important parameter for the location of $\mathrm{Cu}^{2+}$ after ion exchange. Two next-nearest neighboring $\mathrm{Al}$ tetrahedra ("Al pairs") allows best to stabilize divalent cations. ${ }^{38,39}$ The formation of dimeric and trimeric $\mathrm{Cu}$-oxo clusters is proposed to occur on such paired Al sites. ${ }^{14,15,17,40,41}$ The concentration of $\mathrm{Al}$ pairs in the parent $\mathrm{H}-\mathrm{MOR}$ materials can be determined by aqueous $\mathrm{Co}^{2+}$ exchange. ${ }^{38,39}$ Here we have employed two commercial zeolites, MOR-A and MOR-B, that only differ in their $\mathrm{Al}$ distribution, originated by differences in the zeolite synthesis parameters. Table $\mathrm{S} 1$ shows the concentrations of the $\mathrm{Al}$ pairs for H-MOR-A (63\%) and H-MOR-B (66\%). As the number of $\mathrm{Al}$ pairs is nearly identical, the concentration of exchange sites alone is, thus, ruled out as a reason for the higher $\mathrm{Cu}_{\text {eff }}$ of $\mathrm{Cu}$ MOR-B.

The location of the ion exchange sites was determined from the IR spectra of adsorbed $n$-hexane and pyridine on the parent $\mathrm{H}$-MOR samples. $n$-Hexane is only able to interact with BAS in the 12-MR channels (Figure S3). ${ }^{17,42}$ Conversely, the more basic pyridine is protonated by all BAS in 12-MR and in the pore mouth of the 8 -MR side pockets. Table 1 shows clearly that the concentration and location of BAS, as obtained by a 
Table 1. Quantification of Al Species and Their Distribution in the Parent H-MOR-A and H-MOR-B, by a Combination of Chemical Analysis, IR Spectroscopy of $\boldsymbol{n}$-Hexane and Pyridine Adsorption, and ${ }^{27} \mathrm{Al}$ MAS NMR

\begin{tabular}{|c|c|c|}
\hline & H-MOR-A & H-MOR-B \\
\hline total $\mathrm{Al}^{a}(\mu \mathrm{mol} / \mathrm{g})$ & 1440 & 1620 \\
\hline total $\mathrm{BAS}^{b}(\mu \mathrm{mol} / \mathrm{g})$ & $1090^{h}$ & 1130 \\
\hline total $\mathrm{EFAl}^{c}(\mu \mathrm{mol} / \mathrm{g})$ & 350 & 490 \\
\hline $\mathrm{BAS}_{\text {main channel }}{ }^{d}(\mu \mathrm{mol} / \mathrm{g})$ & $400^{h}$ & 419 \\
\hline BAS $_{\text {side-pocket }}{ }^{d}(\mu \mathrm{mol} / \mathrm{g})$ & $690^{h}$ & 706 \\
\hline $\operatorname{LAS}_{\mathrm{Py}}(\mu \mathrm{mol} / \mathrm{g})^{e}$ & $260^{h}$ & 230 \\
\hline $\mathrm{EFAl}_{\text {inaccessible }}{ }^{f}(\mu \mathrm{mol} / \mathrm{g})$ & 90 & 260 \\
\hline $\mathrm{Al}_{\text {tetrahedral }}{ }^{g}(\mu \mathrm{mol} / \mathrm{g})$ & 1156 & 1290 \\
\hline $\mathrm{Al}_{\text {octahedral }} \mathrm{g}(\mu \mathrm{mol} / \mathrm{g})$ & 284 & 330 \\
\hline
\end{tabular}

${ }^{a}$ Total $\mathrm{Al}$ concentration determined by elemental analysis (AAS). ${ }^{b}$ Total BAS concentration determined by elemental analysis after $\mathrm{Na}$ ion exchange of the parent $\mathrm{H}-\mathrm{MOR}$ samples (assuming all $\mathrm{H}^{+}$are exchanged by $\mathrm{Na}^{+}$). ${ }^{c}$ Total EFAl concentration was determined by [total Al] - [total BAS]. ${ }^{d}$ Concentration of BAS located in 12-MR and 8-MR, as determined by deconvolution of the IR band at 3600 $\mathrm{cm}^{-1}$ (Figure S3) after $n$-hexane adsorption. ${ }^{e}$ Concentration of LAS accessible by pyridine, as determined by IR spectroscopy. ${ }^{f}$ Concentration of EFAl located in the inaccessible bottom of 8-MR side pockets was determined by [total EFAl $]-\left[\mathrm{LAS}_{\mathrm{Py}}\right] .{ }^{g}$ Based on ${ }^{27} \mathrm{Al} \mathrm{NMR}$. ${ }^{h}$ Values as reported in ref 17.

combination of these probe molecules, are also similar for $\mathrm{H}$ MOR-A and H-MOR-B. The location of the EFAl species is deduced from both pyridine adsorbed on Lewis acid sites and from the total $\mathrm{Al}$ concentration derived from the elemental analysis. If we assume that Lewis-coordinated pyridine adsorbs in a $1: 1$ ratio to $\mathrm{Al}$ atoms of extra-framework species, the inaccessible EFAl can be calculated as the total measured $\mathrm{Al}$ concentration minus the sum of all BAS (framework Al) and Lewis acid sites (LAS). While the total concentration of LAS determined by pyridine is similar for H-MOR-A and H-MORB (Table 1), the concentration of EFAl in H-MOR-B inaccessible to pyridine was significantly higher than in $\mathrm{H}$ MOR-A. We hypothesize that this inaccessible EFAl is located near the bottom of the 8-MR side pockets.

${ }^{27} \mathrm{Al}$ MAS NMR spectra in Figure S4a show two peaks at 58 and $0 \mathrm{ppm}$, corresponding to tetrahedral and octahedral $\mathrm{Al}$ species. ${ }^{33}$ The octahedral Al fraction was found to account for approximately $20 \%$ of $\mathrm{Al}$ for both parent $\mathrm{H}-\mathrm{MOR}$ samples (Table 1). This concentration of octahedral Al determined by ${ }^{27} \mathrm{Al}$ MAS NMR is smaller than that determined from pyridine adsorption (Table 1), suggesting that some of the EFAl-related Lewis acid sites have tetrahedral coordinated $\mathrm{Al}^{43}$ It should be emphasized that H-MOR-B has about a $3 \times$ higher concentration of inaccessible EFAl than MOR-A.

Location of Exchanged Cu Species in Standard and Highly Active MOR

All samples in this study have more than $90 \%$ of $\mathrm{Cu}$ at ion exchange sites (determined by $\mathrm{Na}^{+}$back-exchange, see Table $\mathrm{S} 2$ in the SI). The preferred exchange sites for $\mathrm{Cu}^{2+}$ in $\mathrm{H}-\mathrm{MOR}$ were determined by analysis of the decrease in intensity of the band of SiOHAl groups at $3600 \mathrm{~cm}^{-1}$ after $\mathrm{Cu}^{2+}$ ion exchange. This band consists of two contributions at 3612 and 3590 $\mathrm{cm}^{-1}$, attributed to BAS in the 12-MR main channel and the 8MR side pockets, respectively. ${ }^{41}$ The preferred sites for ionexchange in MOR are the more constrained 8-MR side pockets. ${ }^{44}$ In Cu-MOR-A, the formation of the active trimeric
$\mathrm{Cu}$-oxo cluster was observed selectively at the pore mouth of the 8-MR side pockets. ${ }^{17}$ Given the similar BAS distribution in H-MOR-A and H-MOR-B (Table 1), it is not surprising that the preferred exchange sites for $\mathrm{Cu}^{2+}$ in the $\mathrm{Cu}-\mathrm{MOR}-\mathrm{B}$ series are also the $\mathrm{Al}$ sites located in the pore mouth of 8 -MR pockets.

However, it should be noted that while in the Cu-MOR-A series about $0.7 \mathrm{BAS}$ were consumed per $\mathrm{Cu}$ ion exchanged, it was approximately 0.9 with the $\mathrm{Cu}-\mathrm{MOR}-\mathrm{B}$ series. The ratio of $0.7 \mathrm{BAS} / \mathrm{Cu}$ in the activated sample has been explained by the location of a tricopper cluster stabilized by two Al tetrahedra. ${ }^{17}$ Thus, the higher involvement of BAS per $\mathrm{Cu}^{2+}$ ion in $\mathrm{Cu}$ MOR-B is a first indication for differences in the speciation of $\mathrm{Cu}$ ions compared to the $\mathrm{A}$ series.

${ }^{27} \mathrm{Al}$ MAS NMR spectra of Cu-MOR-B series shows a significant decrease of octahedral $\mathrm{Al}$, associated with $\mathrm{EFAl}$ with increasing $\mathrm{Cu}$ concentration (Figure $\mathrm{S} 4 \mathrm{~b}$ ). The decrease in intensity for the tetrahedral $\mathrm{Al}$ species is accompanied by a simultaneous line broadening due to the impact of paramagnetic $\mathrm{Cu}^{2+}$. Integration of the peak area corresponding to tetrahedral $\mathrm{Al}$ showed that its concentration remained constant with $\mathrm{Cu}$ loading. The linear decrease of octahedral $\mathrm{Al}$ upon $\mathrm{Cu}$ exchange is, therefore, attributed to the formation of new NMR-silent $\mathrm{Al}$ or, alternatively, to the conversion from octahedral to tetrahedral coordination upon $\mathrm{Cu}$ introduction.

The quantification of $\mathrm{Al}$ species having a different coordination based solely on NMR spectroscopy is subject to uncertainties due to the paramagnetism of $\mathrm{Cu}^{2+33,45,46}$ Therefore, we used Al K-edge XAS to determine and quantify $\mathrm{Al}$ in different coordinations. Figure 3 shows the XANES Al

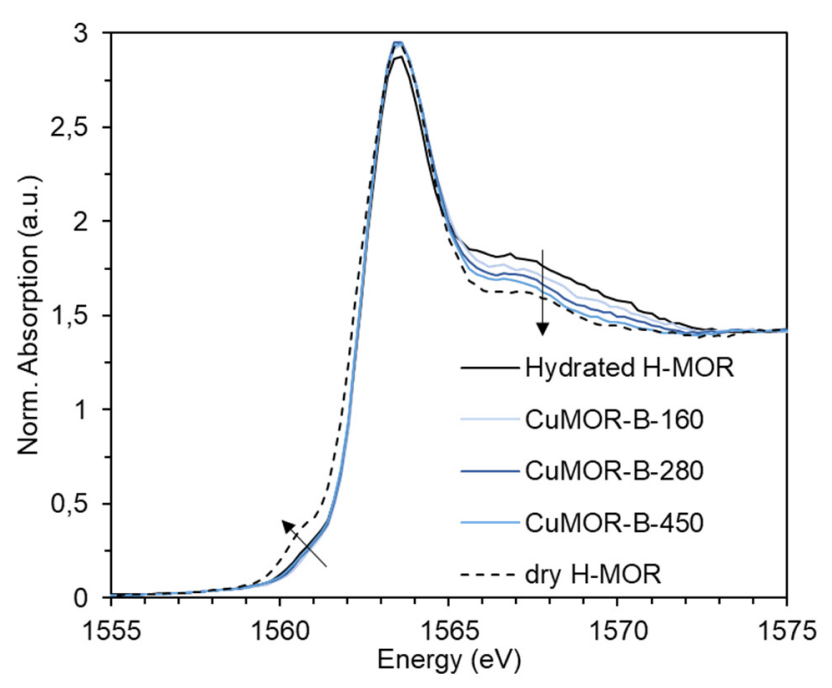

Figure 3. $\mathrm{Al} \mathrm{K}$-edge XANES of $\mathrm{Cu}-\mathrm{MOR}-\mathrm{B}$ series with different $\mathrm{Cu}$ loadings. Measurements were performed in hydrated states unless stated.

spectra for samples of Cu-MOR-B series. The broad peak at $1568 \mathrm{eV}$ decreases with $\mathrm{Cu}$ loading. Because this peak is attributed to $\mathrm{Al}$ in octahedral coordination, ${ }^{47}$ the changes in $\mathrm{Al}$ K-XANES with increasing $\mathrm{Cu}$ loadings are attributed to the gradual transformation of octahedral into tetrahedral Al. $24,47-49$

Linear combination fitting of XANES spectra was used to determine the concentration of tetrahedral and octahedral $\mathrm{Al}$ species. The spectra of dehydrated H-MOR-B was taken as a reference for $0 \%$ octahedral $\mathrm{Al}$, since extra-framework $\mathrm{Al}$ 
changes its coordination from octahedral to tetrahedral upon losing water ligands. A small pre-edge feature at $1560.5 \mathrm{eV}$ appeared with the dehydrated form of H-MOR-B sample due to the localization of $\mathrm{H}^{+}$at the negatively charged framework $\mathrm{Al}$ site, resulting from the loss of $\mathrm{H}_{2} \mathrm{O}$ ligand molecules. ${ }^{49}$ Hydrated H-MOR-B was used as a reference for octahedral $\mathrm{Al}$ quantification, with a concentration of $20 \%$ EFAl, as determined by ${ }^{27} \mathrm{Al}$ MAS NMR. It can be seen from Figure 4 that the concentration of octahedral $\mathrm{Al}$ decreased with

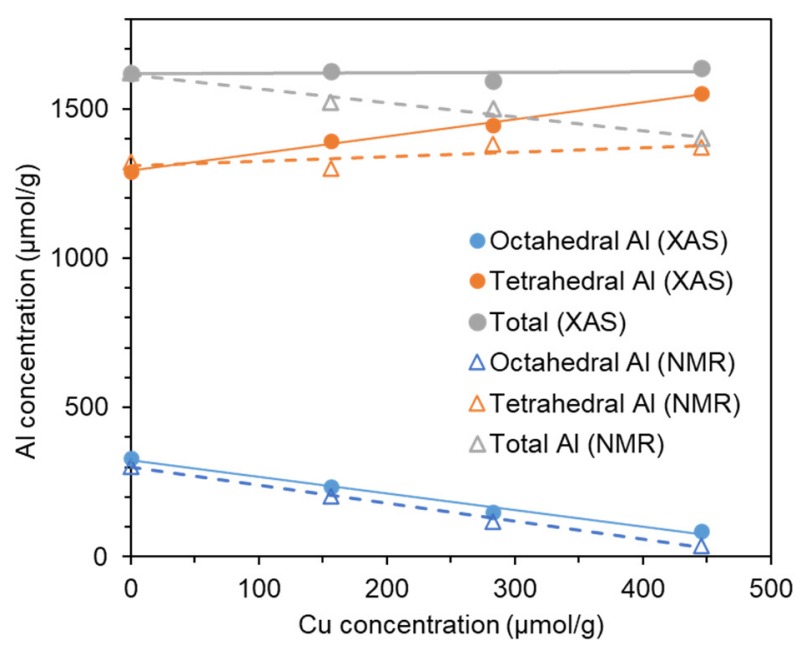

Figure 4. Concentration of tetrahedral, octahedral, and total $\mathrm{Al}$ of hydrated Cu-MOR-B series obtained by LCF of Al K-edge XANES (full symbols) and ${ }^{27} \mathrm{Al}$ NMR measured on a $500 \mathrm{MHz}$ instrument (hollow symbols).

increasing $\mathrm{Cu}$ concentration, in good agreement with ${ }^{27} \mathrm{Al}$ MAS NMR spectra (Figure 4, hollow symbols). The relative amount of tetrahedral $\mathrm{Al}$ linearly increased with increasing $\mathrm{Cu}$ concentration.

These results lead to the hypothesis that the direct interaction of octahedral $\mathrm{Al}$ with $\mathrm{Cu}^{2+}$ ions induces the change in $\mathrm{Al}$ coordination. In view of the calculated concentrations of octahedral Al by XAS and NMR, we conclude that the linear decrease of the octahedral fraction of $\mathrm{Al}$ is mainly due to the change in coordination upon interaction with $\mathrm{Cu}$ ions. In particular, concentrations obtained from $\mathrm{Al}$ XAS analysis (Figure 4) point to the reaction of about two $\mathrm{Cu}$ atoms with one $\mathrm{Al}$. The specific interaction of $\mathrm{Cu}^{2+}$ with octahedral, that is, extra-framework, suggests the formation of tetrahedral $\mathrm{Al}$, and of $\mathrm{CuAl}_{x} \mathrm{O}_{y}$ nanoclusters as a possible structure, with $x=0.5$. X-ray Absorption Spectroscopic Study of Highly Active Cu-MOR Species

In order to investigate a representative member of the $\mathrm{Cu}$ MOR-B series, a sample with a $\mathrm{Cu}$ concentration of $283 \mu \mathrm{mol} /$ $\mathrm{g}$ and $\mathrm{a} \mathrm{Cu}_{\text {eff }}$ of 0.58 was selected for detailed XAS experimental studies in combination with computational studies.

Figure 5 shows the $\mathrm{Cu} \mathrm{K}$-edge and $\mathrm{Cu} \mathrm{L}_{3}$-edge $\mathrm{X}$-ray absorption near edge structure (XANES) of $\mathrm{O}_{2}$ activated $\mathrm{Cu}$ MOR-B-280. The combined use of $\mathrm{K}$ - and $\mathrm{L}_{3}$-edge XANES allows unambiguous determination of the coordination structure and environment of $\mathrm{Cu}$. Using HERFD-XANES resolves spectral features in the $\mathrm{Cu} \mathrm{K}$ edge (Figure 5a) that are not detectable using conventional XANES. ${ }^{50-53}$ However, it must be noted that the peak heights are different between the
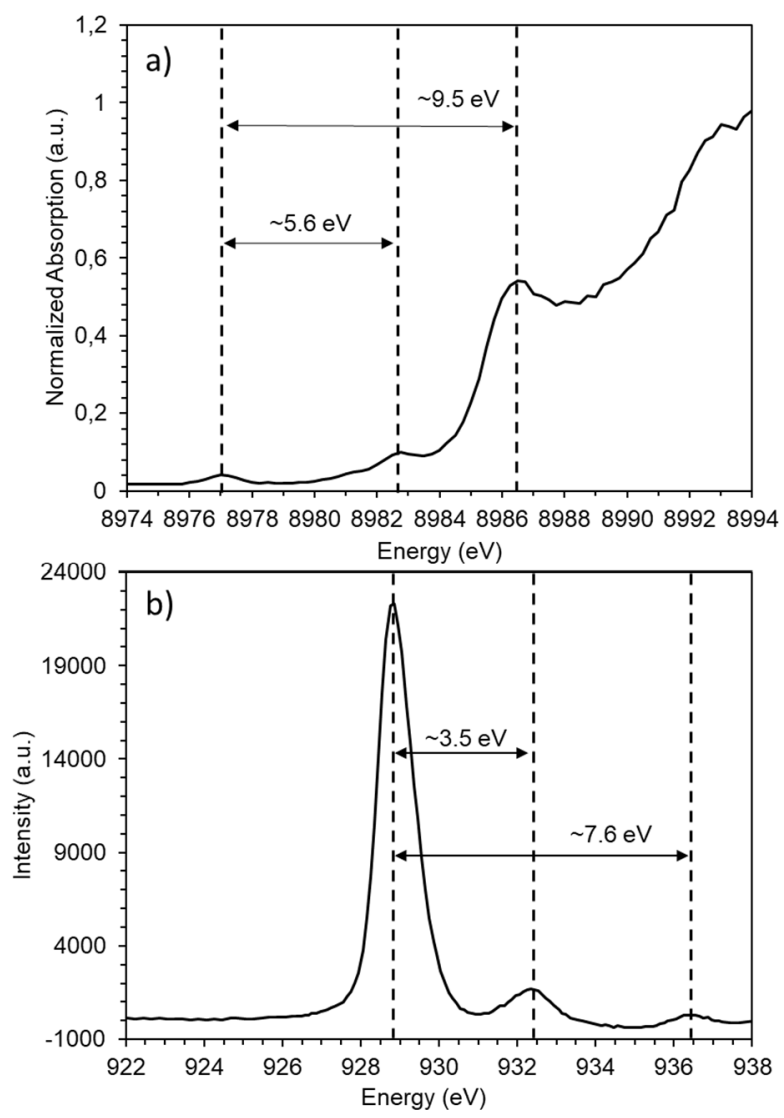

Figure 5. (a) $\mathrm{Cu}$ K-edge HERFD-XANES; (b) $\mathrm{Cu} \mathrm{L}_{3}$-edge XANES of Cu-MOR-B-280 activated in $\mathrm{O}_{2}$ at $450{ }^{\circ} \mathrm{C}$ for $1 \mathrm{~h}$.

two measurements. The $\mathrm{Cu}$ K-edge XANES spectrum is provided for comparison (Figure S5a) in the SI.

In $\mathrm{Cu}$ K-edge XANES the pre-edge peak at about $8977.3 \mathrm{eV}$ is attributed to quadrupole allowed $1 \mathrm{~s}$ to $3 \mathrm{~d}$ transitions. The appearance of the pre-edge feature is an indicator that $\mathrm{Cu}$ species in this $\mathrm{Cu}-\mathrm{MOR}$ material are predominantly $\mathrm{Cu}^{2+}$. Between the pre-edge at $8977.3 \mathrm{eV}$ and the peak at $8986.7 \mathrm{eV}$ $(\Delta E=9.5 \mathrm{eV})$, a peak appeared at about $8982.8 \mathrm{eV}(\Delta E=5.6$ $\mathrm{eV}$; Figures 5a and S5a). The energy corresponds to the $\mathrm{Cu}^{+} 1 \mathrm{~s}$ to $4 \mathrm{p}$ transition and is hypothesized to indicate either presence of $\mathrm{Cu}^{+}$stabilized by the zeolite ${ }^{14,15,41,50}$ or is caused by beam damage due to the larger X-ray dose in HERFD-XANES. ${ }^{54,55}$ In either form, this cation would not be actively involved in $\mathrm{CH}_{4}$ oxidation. Figure $5 \mathrm{~b}$ shows the $\mathrm{L}_{3}$-edge XANES of $\mathrm{Cu}$ MOR-B-280 with the main peak at about $928.8 \mathrm{eV}$ and distinct satellite peaks at about 932.4 and $936.5 \mathrm{eV}$.

Structural Assignment of Cu Species Using AlMD and Simulated $K$ - and $L_{3}$-Edge XANES and EXAFS Spectra

After establishing that $\mathrm{Al}$ is part of the active site, $11 \mathrm{Cu}-\mathrm{Al}-$ oxo and $\mathrm{Cu}-$ oxo clusters have been explored by AIMD simulations. The cluster models studied and the snapshots extracted from AIMD trajectories are shown in Figure S6. AIMD simulations at $298 \mathrm{~K}$ with clusters and $\mathrm{Al}$ atoms at different sites are compiled in Figure S8. As $\mathrm{Cu}^{2+}$ has been established to be located in the 8-MR side pockets of MOR, ${ }^{17,18,56,57}$ only clusters in that location were considered. For a tentative composition of $\mathrm{Cu}_{2} \mathrm{AlO}_{3}$, two configurations are considered, that is, one with the $\mathrm{Al}$ atom away from the MOR surface $(\mathrm{Cu}-\mathrm{Al}-\mathrm{Cu})$ and another with $\mathrm{Al}$ near the surface $(\mathrm{Al}-\mathrm{Cu}-\mathrm{Cu})$. Spin multiplicities were found only to have a 

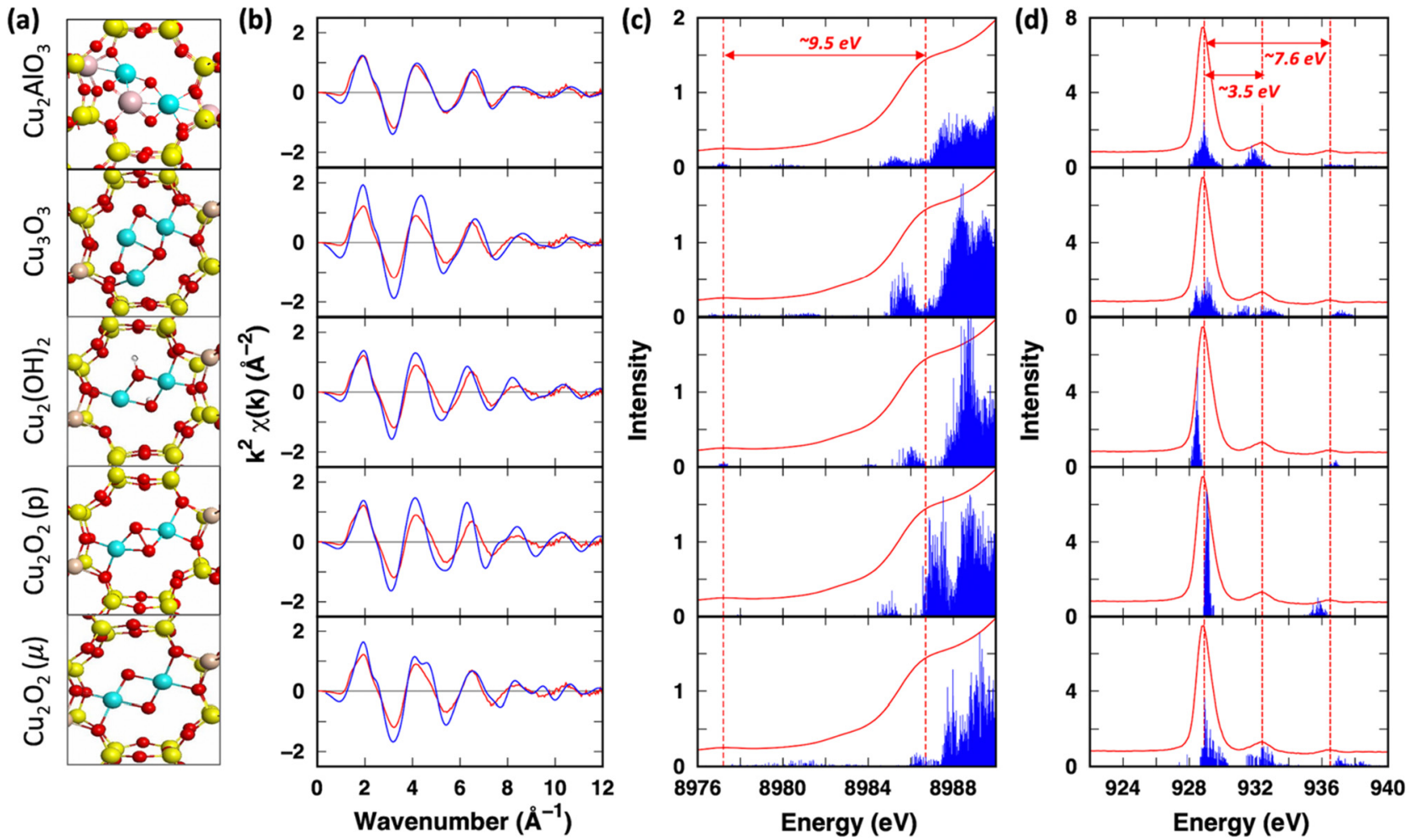

Figure 6. (a) Annealed structure, (b) compared $k^{2}$-weighted EXAFS $\left(k^{2} \chi(k)\right)$ from calculation (blue line) and measurement (red lines), (c) K-edge XANES, and (d) L3-edge XANES spectra of selected systems. For spectra of the $\mathrm{Cu}$ trimer and $\mathrm{Cu}_{2} \mathrm{AlO}_{3}$, we plot ensemble averaged data with different $\mathrm{Al}$ and $\mathrm{Cu}$ cluster sites where individual spectra can be found in Figures $\mathrm{S} 6$ and $\mathrm{S} 8$. K-edge and $\mathrm{L}_{3}$-edge XANES spectra are shifted by 88 and $2.1 \mathrm{eV}$, respectively, in order to match experimental pre-edge and main peak, and their intensities are with arbitrary units. (c) and (d) compare theoretical (blue lines) spectra with experimental ones (red line) along with red vertical guiding lines and energies, as shown in Figure 5a and b, respectively.

minor influence on the results. The simulated systems are listed in Table S3 of the SI. It should be emphasized at this point that the strength of the spectroscopic characterization and the associated modeling lies in the fact that three probes must yield agreement: XANES at the $\mathrm{K}$ - and the $\mathrm{L}_{3}$-edge as well as the K-edge EXAFS. Only this combination provides now the ability of an unequivocal assignment, while each of the approaches alone would remain ambiguous, even when experiment and modeling are combined.

The comparison of both $\mathrm{k}$ - and R-space EXAFS simulated spectra with the experiments indicates that neither $\mathrm{Cu}$ monomers, nor mono-oxo and monohydroxo dicopper clusters or the $\mathrm{Cu}_{2} \mathrm{AlO}_{3}$ cluster with the $\mathrm{Al}-\mathrm{Cu}-\mathrm{Cu}$ configuration are likely structures. For these model clusters EXAFS simulations show large discrepancies with the experimental data obtained on the current samples in peak positions and intensities (Figure S8 in the SI). Figure 6a compiles snapshots of simulated structures having a reasonable agreement with the experiment. Figures $6 \mathrm{~b}$ and S10 show the averaged $\mathrm{k}-$ and Rspace EXAFS, respectively, for these selected structures. In Figure $6 c, d$, we also show the corresponding ensemble averaged $\mathrm{K}$-edge and $\mathrm{L}_{3}$-edge XANES spectra. It should be noted that, for the $\mathrm{Cu}_{3} \mathrm{O}_{3}$ and $\mathrm{Cu}_{2} \mathrm{AlO}_{3}$ clusters in Figure 6, the spectra from $\mathrm{S} 2-\mathrm{S} 4$ sites were averaged (see Figures S8 and S10 in the SI that show the spectra for each site). This allows a reliable comparison with experimental spectra, which likely also represent an average of slightly different locations of the clusters.
Figure $6 \mathrm{~b}$ clearly shows that the calculated $k^{2} \chi(k)$ EXAFS spectra of the $\mathrm{Cu}_{2} \mathrm{AlO}_{3}$ species agrees well with the experimental spectra. This can also be seen for the $\mathrm{R}$-space (Figure $\mathrm{S} 9 \mathrm{a}-\mathrm{c}$ ). The simulated spectra for $\mathrm{Cu}_{3} \mathrm{O}_{3}$ reproduce the positions of the first and second peaks very well, but show higher intensities than the experiment.

For the bis( $\mu$-hydroxo) and peroxo dicopper systems, only the position and intensity of the first peak of $k^{2} \chi(k)$ EXAFS shows a good agreement with experimental data. The $k^{2} \chi(k)$ EXAFS of bis ( $\mu$-oxo) $\mathrm{Cu}$ dimer can be ruled out, therefore, as neither the intensity of the first peak nor the shape of the second peak is reproduced and also scattering above $k=8 \AA^{-1}$ is poorly reproducing the experimental data (Figure S8). The detailed analysis of the EXAFS peaks and their relation to the structure are compiled in section S6 of the SI.

Analysis of K-edge and $\mathrm{L}_{3}$-edge XANES simulated spectra offer further insight in the structure of the active species. Figure $6 c$,d shows the simulated XANES spectra with guiding lines added to facilitate comparisons of the calculated energy difference $(\Delta E)$ with the experimental values (Figure 5 and red line in Figure $6 c, d)$. The simulated K-edge XANES spectra of $\mathrm{Cu}_{2} \mathrm{AlO}_{3}, \mathrm{Cu}_{3} \mathrm{O}_{3}$, and the $\operatorname{bis}(\mu$-oxo $)$ and peroxo $\mathrm{Cu}_{2} \mathrm{O}_{2}$ clusters show a transition at $\Delta E$ greater than $10 \mathrm{eV}$, which is attributed to the dipole allowed $1 \mathrm{~s}$ to $4 \mathrm{p}$ transition, but at higher energies than the experimental value of $9.5 \mathrm{eV}$ (see Figure 5).

All simulated $\mathrm{L}_{3}$-edge XANES spectra show a main peak at $\sim 929 \mathrm{eV}$, corresponding to $\mathrm{Cu}^{2+} 2 \mathrm{p}$ to $3 \mathrm{~d}$ dipole transitions, with distinct satellite features. Simulated $\mathrm{L}_{3}$-edge XANES 
spectrum of $\mathrm{Cu}_{2} \mathrm{AlO}_{3}$ species shows transitions at $\Delta E=\sim 3.3$ and $\sim 7.8 \mathrm{eV}$, which agree well with the features observed at $\Delta E=\sim 3.5$ and $\sim 7.6 \mathrm{eV}$ (Figure $5 \mathrm{~b}$ ). While the $\mathrm{Cu}_{3} \mathrm{O}_{3}$ structure shows a main peak and satellite peaks at $\Delta E$ values similar to the $\mathrm{Cu}_{2} \mathrm{AlO}_{3}$ structure, the additional peak at $\Delta E=$ $\sim 2.0 \mathrm{eV}$ has not been detected in the experiment, and the structure can be ruled out on this basis. For the bis ( $\mu$-hydroxo) and peroxo dimers, the satellite peak at $\Delta E=\sim 3.5 \mathrm{eV}$ was not observed in simulated spectra. Interestingly, for the bis $(\mu$-oxo $)$ dimer, which is ruled out on the basis of the EXAFS calculations, the simulated spectra show energy differences similar to the experiment although with higher peak energies. Based on $\mathrm{L}_{3}$-edge XANES, the spectra calculated for $\mathrm{Cu}_{2} \mathrm{AlO}_{3}$ is consistent with all experimental spectra and is, therefore, concluded to be the most likely structure causing the transformation of methane to methanol; see SI (section S7 and Figure S11) for further discussion. We conclude, therefore, that the activation of $\mathrm{CH}_{4}$ in the highly efficient $\mathrm{Cu}-\mathrm{MOR}$ materials is indeed performed by a $\mathrm{Cu}_{2} \mathrm{AlO}_{3}$ species, with the structure shown in Figure 6a, top. The data suggest that the formation of such $\mathrm{Cu}_{2} \mathrm{AlO}_{3}$ clusters requires the presence of extra-framework alumina at the bottom of the side pocket (i.e., not accessible for pyridine).

\section{CONCLUSIONS}

A series of $\mathrm{Cu}-\mathrm{MOR}$ catalysts with an unprecedently high fraction of $\mathrm{Cu}$ being active in selective methane oxidation to methanol has been synthesized. The activity to form oxidized molecules in a stepwise reaction combined with characterization by NMR, IR, and X-ray absorption spectroscopy point to the formation of $\mathrm{Cu}-\mathrm{Al}$ clusters in the 8-MR side pockets, linking exchanged $\mathrm{Cu}^{2+}$ species with extra-framework $\mathrm{Al}$ moieties that were originally located at the bottom of the side pocket of MOR.

The combined experiment and simulation of $\mathrm{Cu} \mathrm{K}$ and $\mathrm{L}_{3}$ XANES together with EXAFS spectra allows unequivocally identifying the oxide clusters to consist of two $\mathrm{Cu}$ atoms and one Al atom linked by oxygen (Figure 6a). This cluster is located in the side pocket and shows the ability to oxidize 1.2 methane molecules on average when exposed to 1 bar of methane. Therefore, the amount of $\mathrm{CH}_{4}$ activated per $\mathrm{Cu}$ in these materials corresponds to the utilization of one to up to two $\mathrm{O}$ atoms per cluster, analogous to the variations in reactivity observed for $\mu$-oxo species in $\mathrm{Cu}_{3} \mathrm{O}_{3}$ clusters with chemical potential. ${ }^{22}$ However, we cannot unambiguously rule out the presence of a minority species, a highly active $\mathrm{Cu}$-oxo cluster with $\mathrm{Cu}_{\text {eff }}>0.5$, that could also account for the excess of $\mathrm{CH}_{4}$ activated.

At present, we can only speculate about the reason for the higher reactivity of the oxygen or the easier reducibility of $\mathrm{Cu}^{2+}$ in the $\left[\mathrm{Cu}_{2} \mathrm{AlO}_{3}\right]^{2+}$ cluster. One of the currently preferred hypotheses is that the distortion of the cluster decreases the stability of the $\mathrm{Me}-\mathrm{O}$ bond strength. Detailed calculations on the chemical reactivity are currently being performed, but the discussion of these aspects is beyond the scope of the current paper.

\section{EXPERIMENTAL AND COMPUTATIONAL METHODS}

\section{Preparation of Cu-MOR Samples}

Commercial $\mathrm{NH}_{4}$-MOR $(\mathrm{Si} / \mathrm{Al}=10$ and 11$)$ were purchased by Clariant, and the corresponding $\mathrm{H}$-form was obtained after calcination in synthetic air $(100 \mathrm{~mL} / \mathrm{min})$ at $550{ }^{\circ} \mathrm{C}(10 \mathrm{~K} / \mathrm{min})$ for $6 \mathrm{~h}$. The $\mathrm{H}$ MOR samples with $\mathrm{Si} / \mathrm{Al}=11$ and 10 were denoted as H-MOR-A and H-MOR-B. Cu-MOR samples were prepared by aqueous ion exchange of $\mathrm{H}-\mathrm{MOR}$ at ambient temperature in aqueous solutions of $\mathrm{Cu}\left(\mathrm{CH}_{3} \mathrm{COO}\right)_{2}$ (Sigma-Aldrich, 99.99\%) for $20 \mathrm{~h}$. The $\mathrm{pH}$ of the solution was kept to 5.5-6.0 with during the $\mathrm{Cu}$-exchange. $\mathrm{Si}, \mathrm{Al}, \mathrm{Na}$, and $\mathrm{Cu}$ contents were measured by atomic absorption spectroscopy (AAS) on a UNICAM 939 AA spectrometer after dissolution in boiling hydrofluoric acid.

Activity Tests in Selective Oxidation of $\mathrm{CH}_{4}$

The activity was tested under atmospheric pressure in a stainless steel plug flow reactor with a $4 \mathrm{~mm}$ inner diameter. In a typical reaction, 50 mg of Cu-MOR was first activated for $1 \mathrm{~h}$ in $\mathrm{O}_{2}$ at $500{ }^{\circ} \mathrm{C}$, cooled down to $200{ }^{\circ} \mathrm{C}$, and then flushed with $\mathrm{He}$. In the next step, $90 \% \mathrm{CH}_{4}$ in $\mathrm{He}$ was flown over the sample for $4 \mathrm{~h}$. The samples were then cooled to $135{ }^{\circ} \mathrm{C}$ in $\mathrm{He}$ and a steam-assisted product desorption was performed with $50 \% \mathrm{H}_{2} \mathrm{O}$ in $\mathrm{He}$. Reaction products were identified and quantified with online mass spectroscopy by monitoring the $\mathrm{m} / \mathrm{z}$ signals of 31,44 , and 46 for $\mathrm{CH}_{3} \mathrm{OH}, \mathrm{CO}_{2}$, and $\left(\mathrm{CH}_{3}\right)_{2} \mathrm{O}$, respectively.

\section{In Situ Infrared (IR) Spectroscopy}

The samples for IR spectroscopy were pressed as self-supporting wafers with a density of about $10 \mathrm{mg} / \mathrm{cm}^{2}$ and activated in vacuum $\left(1.0 \times 10^{-7} \mathrm{mbar}\right)$ at $450{ }^{\circ} \mathrm{C}$ with a heating rate of $10 \mathrm{~K} / \mathrm{min}$ for $1 \mathrm{~h}$. IR spectroscopy of pyridine adsorption were measured on Thermo Nicolet 5700 FT-IR spectrometer with a resolution of $4 \mathrm{~cm}^{-1}$. The measurements were performed before and after pyridine adsorption at $150{ }^{\circ} \mathrm{C}$.

\section{${ }^{27}$ Al Magic-Angle Spinning (MAS) Nuclear Magnetic Resonance (NMR) Spectroscopy}

${ }^{27} \mathrm{Al}$ MAS NMR spectra were recorded on a Bruker Avance 500 Ultrashield NMR spectrometer with a magnetic field of $11.75 \mathrm{~T}$ corresponding to the Lamor frequency of $130.3 \mathrm{MHz}$ and the rotor was spun at $12 \mathrm{kHz} .2400$ spectra were accumulated in a single pulse sequence with a pulse width of $1.16 \mu \mathrm{s}$ and the relaxation delay of $2 \mathrm{~s}$. Parent H-MOR zeolites were measured on a Varian-Agilent Inova 63 $\mathrm{mm}$ wide-bore $900 \mathrm{MHz}$ NMR spectrometer. The samples were packed in a $3.2 \mathrm{~mm}$ pencil type MAS probe with a magnetic field of $21.1 \mathrm{~T}$, corresponding to the Lamor frequency of $234.56 \mathrm{MHz}$ and the rotor was spun at $20 \mathrm{kHz}$. A total of 5000 scans were recorded in a single pulse sequence with a pulse length of $2.0 \mu$ s and relaxation delay of $1 \mathrm{~s}$.

\section{Al K-Edge and Cu L-Edge XAFS}

$\mathrm{X}$-ray absorption spectra at $\mathrm{Al} \mathrm{K}$-edge and $\mathrm{Cu} \mathrm{L}$-edge spectra were measured at the Swiss Light Source (SLS) of the Paul Scherrer Institut (Villigen, Swiss) on PHOENIX II. All measurements were carried out in fluorescence mode. X-ray fluorescence signal was detected by an one-element energy dispersive Silicon drift diode (DSS, manufacturer KeteK, Germany). The introduced gases were further dried by using Supelco 5A Moisture trap. ATHENA software was used during the background processing. XANES normalization follows standard protocol used within the Athena software. ${ }^{58}$

\section{Cu K-Edge XANES}

HERFD XANES measurements were carried on beamline P64 at PETRA III of DESY (Hamburg, Germany). Conventional Cu K-edge XANES measurements were carried out on beamline P65 at PETRA III of DESY in Hamburg, Germany. A double-crystal Si(111) monochromator was used to control the incident photon energy, and the spectra were recorded with ionization chamber detectors in the transmission mode. The gases were further dried by using Supelco 5A Moisture trap. ATHENA software was used during the background processing. XANES normalization follows standard protocol used within the Athena software. ${ }^{58}$

Further details of the experimental methods are provided in the section S1 of the Supporting Information. 


\section{DFT Calculations}

Periodic spin-polarized density functional theory (DFT) calculations are performed within the generalized gradient approximation (GGA) with the exchange correlation functional of Perdew, Burke, and Ernzerhoff $(\mathrm{PBE})^{59}$ as implemented in the CP2K package. ${ }^{60,61}$ Grimme's third-generation corrections (DFT-D3) are used to take into account dispersion forces or van der Waals interactions to describe energies more precisely. ${ }^{62}$ For the core electrons, Goedecker-Teter-Hutter (GTH) pseudopotentials are used, ${ }^{63}$ while the valence wave functions are expanded in terms of double- $\zeta$ quality basis sets optimized for condensed systems to minimize linear dependencies and superposition errors. ${ }^{64}$ Electrostatic terms are calculated using an additional auxiliary plane-wave basis set with a 400 Ry cutoff. The $\Gamma$-point approximation is employed for the Brillouin zone integration because of the significant size of the supercell.

AIMD Simulations. Starting with a cell-optimized mordenite supercell, DFT-based ab initio molecular dynamics (AIMD) simulations are performed within the canonical NVT ensemble at room temperature using al.0 fs time step and a Nosé-Hoover chain thermostat with a frequency of $1500 \mathrm{~cm}^{-1}$ to control the temperature to determine the local structure and their dynamic properties. We considered the different spin multiplicities for each system. For each simulation, well-equilibrated trajectories of $\geq 35$ ps were collected to obtain reliable statistical properties.

EXAFS Simulations. We simulated K-edge EXAFS spectra with FEFF8.5 program $^{65}$ using $\geq 500$ snapshots extracted from NVT trajectories with equally spaced by $\sim 0.05$ ps for each system. For each system, each snapshot was used to calculate a full set of scattering (single and multiple scattering) paths for all atoms within $6.5 \AA$ of each $\mathrm{Cu}$ site using FEFF8.5 program. ${ }^{65}$

XANES Calculations with Time-Dependent DFT. Excited-state XANES calculations were performed at the $\mathrm{Cu} \mathrm{K}$ - and $\mathrm{L}_{3}$-edge for selected systems screened from a comparison of experimental and simulated XANES spectra using a TDDFT-based restricted excitation window approach, ${ }^{6,67}$ as implemented in the NWChem quantum chemistry program. ${ }^{66,68}$ All calculated spectra were Lorentzianbroadened by 0.6 . The ensemble averaged TDDFT XANES spectra were generated from $>50$ structures that were equally spaced by 0.5 ps.

Further details of the computational methods are provided in section S4 of the Supporting Information.

\section{ASSOCIATED CONTENT}

\section{Supporting Information}

The Supporting Information is available free of charge at https://pubs.acs.org/doi/10.1021/jacsau.1c00196.

S1: Materials and experimental methods; S2: Additional activity results; S3: Characterization of parent MOR zeolites and Cu-MOR series; S4: Computational details; S5: Structural changes during AIMD simulations; S6: A detailed analysis of the EXAFS peaks and their relation to the structure; S7: Tri-coordinated $\mathrm{Cu}$ on $\mathrm{Cu}_{2} \mathrm{AlO}_{3}$; S8: Coordinates of annealed structures; Supplementary references (PDF)

\section{AUTHOR INFORMATION}

\section{Corresponding Authors}

Johannes A. Lercher - Department of Chemistry and Catalysis Research Center, TU München, 85748 Garching, Germany; Institute for Integrated Catalysis, Pacific Northwest National Laboratory, Richland, Washington 99354, United States; 이이이.org/0000-0002-2495-1404; Email: johannes.lercher@pnnl.gov

Maricruz Sanchez-Sanchez - Department of Chemistry and Catalysis Research Center, TU München, 85748 Garching,
Germany; 이잉.org/0000-0002-3769-9623;

Email: m.sanchez@tum.de

Mal-Soon Lee - Institute for Integrated Catalysis, Pacific Northwest National Laboratory, Richland, Washington 99354, United States; 다이.org/0000-0001-6851-177X; Email: malsoon.lee@pnnl.gov

\section{Authors}

Insu Lee - Department of Chemistry and Catalysis Research Center, TU München, 85748 Garching, Germany

Lei Tao - Department of Chemistry and Catalysis Research Center, TU München, 85748 Garching, Germany

Takaaki Ikuno - Department of Chemistry and Catalysis Research Center, TU München, 85748 Garching, Germany

Rachit Khare - Department of Chemistry and Catalysis Research Center, TU München, 85748 Garching, Germany; () orcid.org/0000-0002-1519-5184

Andreas Jentys - Department of Chemistry and Catalysis Research Center, TU München, 85748 Garching, Germany; (1) orcid.org/0000-0001-5877-5042

Thomas Huthwelker - Swiss Light Source, Laboratory for Synchrotron Radiation and Femtochemistry (LSF), 5232 Villigen, Switzerland

Camelia N. Borca - Swiss Light Source, Laboratory for Synchrotron Radiation and Femtochemistry (LSF), 5232 Villigen, Switzerland

Aleksandr Kalinko - Photon Science DESY, 22607 Hamburg, Germany

Oliver Y. Gutiérrez - Institute for Integrated Catalysis, Pacific Northwest National Laboratory, Richland, Washington 99354, United States

Niri Govind - Physical Sciences Division, Pacific Northwest National Laboratory, Richland, Washington 99354, United States; (1) orcid.org/0000-0003-3625-366X

John L. Fulton - Institute for Integrated Catalysis, Pacific Northwest National Laboratory, Richland, Washington 99354, United States; (1) orcid.org/0000-0001-9361-9803

Jian Zhi Hu - Institute for Integrated Catalysis, Pacific Northwest National Laboratory, Richland, Washington 99354, United States; 이이.org/0000-0001-8879-747X

Vassiliki-Alexandra Glezakou - Institute for Integrated Catalysis, Pacific Northwest National Laboratory, Richland, Washington 99354, United States; 이이.org/0000-00016028-7021

Roger Rousseau - Institute for Integrated Catalysis, Pacific Northwest National Laboratory, Richland, Washington 99354, United States; — orcid.org/0000-0003-1947-0478

Complete contact information is available at: https://pubs.acs.org/10.1021/jacsau.1c00196

\section{Author Contributions}

${ }^{\dagger}$ These authors contributed equally to this work. Notes

The authors declare no competing financial interest.

\section{ACKNOWLEDGMENTS}

I.L., T.I., L.T., M.S.-S., and J.A.L. are thankful to the Deutsche Forschungsgemeinschaft (DFG, Project Number 326562156) and the TUM International Graduate School of Science and Engineering (IGSSE) for financial support. M.-S.L., O.Y.G., J.L.F., J.Z.H., V.-A.G., R.R., and J.A.L. were supported by the U.S. Department of Energy (DOE), Office of Science, Office of 
Basic Energy Sciences, Division of Chemical Sciences, Geosciences and Biosciences (Transdisciplinary Approaches to Realize Novel Catalytic Pathways to Energy Carriers, FWP 47319). Computational work was performed using the Molecular Sciences Computing Facility (MSCF) in the William R. Wiley Environmental Molecular Sciences Laboratory, a U.S. Department of Energy (DOE) national scientific user facility sponsored by the DOE's Office of Biological and Environmental Research and located and the Pacific Northwest National Laboratory (PNNL) and the National Energy Research Scientific Computing Center (NERSC) located at Lawrence Berkley National Laboratory provided by a user proposal. PNNL is operated by Battelle for DOE. We acknowledge DESY beamlines P-64 and P-65 (Hamburg, Germany), a member of the Helmholtz Association HGF, for the provision of experimental facilities for X-ray experiments. The used infrastructure of the von Hamos spectrometer at the beamline P64 was realized in the frame of Projects FKZ 05K13UK1 and FKZ 05K14PP1. A.J. and R.K. were supported by $\mathrm{BMBF}$ under Project MatDynamics (Verbundprojekt 05K13W03). We acknowledge the Paul Scherrer Institut, Villigen, Switzerland, for the provision of synchrotron beamtime at beamline PHOENIX of the SLS. The authors thank Matthias Bauer for his assistance.

\section{REFERENCES}

(1) Caballero, A.; Perez, P. J. Methane as raw material in synthetic chemistry: the final frontier. Chem. Soc. Rev. 2013, 42, 8809-8820.

(2) Alvarez-Galvan, M. C.; Mota, N.; Ojeda, M.; Rojas, S.; Navarro, R. M.; Fierro, J. L. G. Direct methane conversion routes to chemicals and fuels. Catal. Today 2011, 171, 15-23.

(3) Newton, M. A.; Knorpp, A. J.; Sushkevich, V. L.; Palagin, D.; van Bokhoven, J. A. Active sites and mechanisms in the direct conversion of methane to methanol using $\mathrm{Cu}$ in zeolitic hosts: a critical examination. Chem. Soc. Rev. 2020, 49, 1449-1486.

(4) Malakoff, D. The gas surge. Science 2014, 344, 1464.

(5) Olah, G. A. Beyond Oil and Gas: The Methanol Economy. Angew. Chem., Int. Ed. 2005, 44, 2636-2639.

(6) Ma, Y.; Cheng, S.; Wu, X.; Shi, Y.; Cao, L.; Liu, L.; Ran, R.; Si, Z.; Liu, J.; Weng, D. Low-Temperature Solid-State Ion-Exchange Method for Preparing Cu-SSZ-13 Selective Catalytic Reduction Catalyst. ACS Catal. 2019, 9, 6962-6973.

(7) Ravi, M.; Ranocchiari, M.; van Bokhoven, J. A. The Direct Catalytic Oxidation of Methane to Methanol-A Critical Assessment. Angew. Chem., Int. Ed. 2017, 56, 16464-16483.

(8) Groothaert, M. H.; van Bokhoven, J. A.; Battiston, A. A.; Weckhuysen, B. M.; Schoonheydt, R. A. Bis $(\mu$-oxo $)$ dicopper in $\mathrm{Cu}$ ZSM-5 and Its Role in the Decomposition of NO: A Combined in Situ XAFS, UV-Vis-Near-IR, and Kinetic Study. J. Am. Chem. Soc. 2003, 125, 7629-7640.

(9) Park, M. B.; Ahn, S. H.; Mansouri, A.; Ranocchiari, M.; van Bokhoven, J. A. Comparative Study of Diverse Copper Zeolites for the Conversion of Methane into Methanol. ChemCatChem 2017, 9, 3705-3713.

(10) Groothaert, M. H.; Smeets, P. J.; Sels, B. F.; Jacobs, P. A.; Schoonheydt, R. A. Selective Oxidation of Methane by the $\operatorname{Bis}(\mu$ oxo)dicopper Core Stabilized on ZSM-5 and Mordenite Zeolites. J. Am. Chem. Soc. 2005, 127, 1394-1395.

(11) Alayon, E. M. C.; Nachtegaal, M.; Bodi, A.; Ranocchiari, M.; van Bokhoven, J. A. Bis ( $\mu$-oxo) versus mono( $\mu$-oxo $)$ dicopper cores in a zeolite for converting methane to methanol: an in situ XAS and DFT investigation. Phys. Chem. Chem. Phys. 2015, 17, 7681-7693.

(12) Alayon, E. M. C.; Nachtegaal, M.; Bodi, A.; van Bokhoven, J. A. Reaction conditions of methane-to-methanol conversion affect the structure of active copper sites. ACS Catal. 2014, 4, 16-22.
(13) Vanelderen, P.; Snyder, B. E. R.; Tsai, M.-L.; Hadt, R. G.; Vancauwenbergh, J.; Coussens, O.; Schoonheydt, R. A.; Sels, B. F.; Solomon, E. I. Spectroscopic Definition of the Copper Active Sites in Mordenite: Selective Methane Oxidation. J. Am. Chem. Soc. 2015, 137, 6383-6392.

(14) Brezicki, G.; Kammert, J. D.; Gunnoe, T. B.; Paolucci, C.; Davis, R. J. Insights into the Speciation of $\mathrm{Cu}$ in the $\mathrm{Cu}-\mathrm{H}$-Mordenite Catalyst for the Oxidation of Methane to Methanol. ACS Catal. 2019, 9, 5308-5319.

(15) Pappas, D. K.; Martini, A.; Dyballa, M.; Kvande, K.; Teketel, S.; Lomachenko, K. A.; Baran, R.; Glatzel, P.; Arstad, B.ør.; Berlier, G.; Lamberti, C.; Bordiga, S.; Olsbye, U.; Svelle, S.; Beato, P.; Borfecchia, E. The Nuclearity of the Active Site for Methane to Methanol Conversion in Cu-Mordenite: A Quantitative Assessment. J. Am. Chem. Soc. 2018, 140, 15270-15278.

(16) Ikuno, T.; Grundner, S.; Jentys, A.; Li, G.; Pidko, E.; Fulton, J.; Sanchez-Sanchez, M.; Lercher, J. A. Formation of Active Cu-oxo Clusters for Methane Oxidation in Cu-Exchanged Mordenite. J. Phys. Chem. C 2019, 123, 8759-8769.

(17) Grundner, S.; Markovits, M. A.C.; Li, G.; Tromp, M.; Pidko, E. A.; Hensen, E. J.M.; Jentys, A.; Sanchez-Sanchez, M.; Lercher, J. A. Single-site trinuclear copper oxygen clusters in mordenite for selective conversion of methane to methanol. Nat. Commun. 2015, 6, 7546.

(18) Grundner, S.; Luo, W.; Sanchez-Sanchez, M.; Lercher, J. A. Synthesis of single-site copper catalysts for methane partial oxidation. Chem. Commun. 2016, 52, 2553-2556.

(19) Kim, Y.; Kim, T. Y.; Lee, H.; Yi, J. Distinct activation of CuMOR for direct oxidation of methane to methanol. Chem. Commun. 2017, 53, 4116-4119.

(20) Latimer, A. A.; Kulkarni, A. R.; Aljama, H.; Montoya, J. H.; Yoo, J. S.; Tsai, C.; Abild-Pedersen, F.; Studt, F.; Nørskov, J. K. Understanding trends in $\mathrm{C}-\mathrm{H}$ bond activation in heterogeneous catalysis. Nat. Mater. 2017, 16, 225-229.

(21) Snyder, B. E. R.; Vanelderen, P.; Schoonheydt, R. A.; Sels, B. F.; Solomon, E. I. Second-Sphere Effects on Methane Hydroxylation in Cu-Zeolites. J. Am. Chem. Soc. 2018, 140, 9236-9243.

(22) Zheng, J.; Lee, I.; Khramenkova, E.; Wang, M.; Peng, B.; Gutierrez, O. Y.; Fulton, J. L.; Camaioni, D. M.; Khare, R.; Jentys, A.; Haller, G. L.; Pidko, E. A.; Sanchez-Sanchez, M.; Lercher, J. A. Importance of Methane Chemical Potential for Its Conversion to Methanol on Cu-Exchanged Mordenite. Chem. - Eur. J. 2020, 26, $7563-7567$.

(23) Xu, B.; Rotunno, F.; Bordiga, S.; Prins, R.; van Bokhoven, J. A. Reversibility of structural collapse in zeolite Y: Alkane cracking and characterization. J. Catal. 2006, 241, 66-73.

(24) van Bokhoven, J. A.; van der Eerden, A. M. J.; Koningsberger, D. C. Three-Coordinate Aluminum in Zeolites Observed with In situ $\mathrm{X}$-ray Absorption Near-Edge Spectroscopy at the Al K-Edge: Flexibility of Aluminum Coordinations in Zeolites. J. Am. Chem. Soc. 2003, 125, 7435-7442.

(25) Yu, Z.; Zheng, A.; Wang, Q.; Chen, L.; Xu, J.; Amoureux, J.-P.; Deng, F. Insights into the Dealumination of Zeolite HY Revealed by Sensitivity-Enhanced 27Al DQ-MAS NMR Spectroscopy at High Field. Angew. Chem., Int. Ed. 2010, 49, 8657-8661.

(26) van Bokhoven, J. A.; Koningsberger, D. C.; Kunkeler, P.; van Bekkum, H.; Kentgens, A. P. M. Stepwise Dealumination of Zeolite Beta at Specific T-Sites Observed with 27Al MAS and 27Al MQMAS NMR. J. Am. Chem. Soc. 2000, 122, 12842-12847.

(27) Agostini, G.; Lamberti, C.; Palin, L.; Milanesio, M.; Danilina, N.; Xu, B.; Janousch, M.; van Bokhoven, J. A. In Situ XAS and XRPD Parametric Rietveld Refinement To Understand Dealumination of $\mathrm{Y}$ Zeolite Catalyst. J. Am. Chem. Soc. 2010, 132, 667-678.

(28) Yi, X.; Liu, K.; Chen, W.; Li, J.; Xu, S.; Li, C.; Xiao, Y.; Liu, H.; Guo, X.; Liu, S.-B.; Zheng, A. Origin and Structural Characteristics of Tri-coordinated Extra-framework Aluminum Species in Dealuminated Zeolites. J. Am. Chem. Soc. 2018, 140, 10764-10774.

(29) Liu, C.; Li, G.; Hensen, E. J. M.; Pidko, E. A. Relationship between acidity and catalytic reactivity of faujasite zeolite: A periodic DFT study. J. Catal. 2016, 344, 570-577. 
(30) Schallmoser, S.; Ikuno, T.; Wagenhofer, M. F.; Kolvenbach, R.; Haller, G. L.; Sanchez-Sanchez, M.; Lercher, J. A. Impact of the local environment of Brønsted acid sites in ZSM- 5 on the catalytic activity in n-pentane cracking. J. Catal. 2014, 316, 93-102.

(31) van Bokhoven, J. A.; Tromp, M; Koningsberger, D. C.; Miller, J. T.; Pieterse, J. A. Z.; Lercher, J. A.; Williams, B. A.; Kung, H. H. An Explanation for the Enhanced Activity for Light Alkane Conversion in Mildly Steam Dealuminated Mordenite: The Dominant Role of Adsorption. J. Catal. 2001, 202, 129-140.

(32) Liu, C.; Li, G.; Hensen, E. J. M.; Pidko, E. A. Nature and Catalytic Role of Extraframework Aluminum in Faujasite Zeolite: A Theoretical Perspective. ACS Catal. 2015, 5, 7024-7033.

(33) Dyballa, M.; Pappas, D. K.; Kvande, K.; Borfecchia, E.; Arstad, B.ør.; Beato, P.; Olsbye, U.; Svelle, S. On How Copper Mordenite Properties Govern the Framework Stability and Activity in the Methane-to-Methanol Conversion. ACS Catal. 2019, 9, 365-375.

(34) Hämäläinen, K.; Siddons, D. P.; Hastings, J. B.; Berman, L. E. Elimination of the inner-shell lifetime broadening in $\mathrm{x}$-ray-absorption spectroscopy. Phys. Rev. Lett. 1991, 67, 2850-2853.

(35) Qayyum, M. F.; Sarangi, R.; Fujisawa, K.; Stack, T. D. P.; Karlin, K. D.; Hodgson, K. O.; Hedman, B.; Solomon, E. I. L-Edge Xray Absorption Spectroscopy and DFT Calculations on $\mathrm{Cu}_{2} \mathrm{O}_{2}$ Species: Direct Electrophilic Aromatic Attack by Side-on Peroxo Bridged Dicopper(II) Complexes. J. Am. Chem. Soc. 2013, 135, 17417-17431.

(36) Aprà, E.; Bylaska, E. J.; de Jong, W. A.; Govind, N.; Kowalski, K.; Straatsma, T. P.; Harrison, R. J.; et al. NWChem: Past, present, and future. J. Chem. Phys. 2020, 152, 184102.

(37) Tao, L.; Lee, I.; Sanchez-Sanchez, M. Cu oxo nanoclusters for direct oxidation of methane to methanol: formation, structure and catalytic performance. Catal. Sci. Technol. 2020, 10, 7124-7141.

(38) Dedecek, J.; Kaucky, D.; Wichterlova, B.; Gonsiorova, O. Co2+ ions as probes of $\mathrm{Al}$ distribution in the framework of zeolites. ZSM-5 study. Phys. Chem. Chem. Phys. 2002, 4, 5406-5413.

(39) Dědeček, J.; Sobalík, Z.; Wichterlová, B. Siting and Distribution of Framework Aluminium Atoms in Silicon-Rich Zeolites and Impact on Catalysis. Catal. Rev.: Sci. Eng. 2012, 54, 135-223.

(40) Markovits, M. A. C.; Jentys, A.; Tromp, M.; Sanchez-Sanchez, M.; Lercher, J. A. Effect of Location and Distribution of Al Sites in ZSM-5 on the Formation of Cu-Oxo Clusters Active for Direct Conversion of Methane to Methanol. Top. Catal. 2016, 59, 15541563.

(41) Pappas, D. K.; Borfecchia, E.; Dyballa, M.; Pankin, I. A.; Lomachenko, K. A.; Martini, A.; Signorile, M.; Teketel, S.; Arstad, B.ør.; Berlier, G.; Lamberti, C.; Bordiga, S.; Olsbye, U.; Lillerud, K. P.; Svelle, S.; Beato, P. Methane to Methanol: Structure-Activity Relationships for Cu-CHA. J. Am. Chem. Soc. 2017, 139, 1496114975 .

(42) Eder, F.; Stockenhuber, M.; Lercher, J. A. Brønsted Acid Site and Pore Controlled Siting of Alkane Sorption in Acidic Molecular Sieves. J. Phys. Chem. B 1997, 101, 5414-5419.

(43) Triantafillidis, C. S.; Vlessidis, A. G.; Evmiridis, N. P. Dealuminated H-Y Zeolites: Influence of the Degree and the Type of Dealumination Method on the Structural and Acidic Characteristics of H-Y Zeolites. Ind. Eng. Chem. Res. 2000, 39, 307-319.

(44) Veefkind, V. A.; Smidt, M. L.; Lercher, J. A. On the role of strength and location of Brønsted acid sites for ethylamine synthesis on mordenite catalysts. Appl. Catal., A 2000, 194-195, 319-332.

(45) Kwak, J. H.; Tran, D.; Burton, S. D.; Szanyi, J.; Lee, J. H.; Peden, C. H. F. Effects of hydrothermal aging on NH3-SCR reaction over $\mathrm{Cu}$ /zeolites. J. Catal. 2012, 287, 203-209.

(46) Beale, A. M.; Gao, F.; Lezcano-Gonzalez, I.; Peden, C. H. F.; Szanyi, J. Recent advances in automotive catalysis for NOx emission control by small-pore microporous materials. Chem. Soc. Rev. 2015, 44, 7371-7405.

(47) Drake, I. J.; Zhang, Y.; Gilles, M. K.; Teris Liu, C. N.; Nachimuthu, P.; Perera, R. C. C.; Wakita, H.; Bell, A. T. An In Situ Al K-Edge XAS Investigation of the Local Environment of $\mathrm{H}+-$ and $\mathrm{Cu}$
+-Exchanged USY and ZSM-5 Zeolites. J. Phys. Chem. B 2006, 110, 11665-11676.

(48) Bugaev, L. A.; van Bokhoven, J. A.; Sokolenko, A. P.; Latokha, Y. V.; Avakyan, L. A. Local Structure of Aluminum in Zeolite Mordenite as Affected by Temperature. J. Phys. Chem. B 2005, 109, 10771-10778.

(49) Vjunov, A.; Wang, M.; Govind, N.; Huthwelker, T.; Shi, H.; Mei, D.; Fulton, J. L.; Lercher, J. A. Tracking the Chemical Transformations at the Brønsted Acid Site upon Water-Induced Deprotonation in a Zeolite Pore. Chem. Mater. 2017, 29, 9030-9042.

(50) Alayon, E. M. C.; Nachtegaal, M.; Kleymenov, E.; van Bokhoven, J. A. Determination of the electronic and geometric structure of $\mathrm{Cu}$ sites during methane conversion over $\mathrm{Cu}-\mathrm{MOR}$ with $\mathrm{X}$-ray absorption spectroscopy. Microporous Mesoporous Mater. 2013, $166,131-136$

(51) Günter, T.; Doronkin, D. E.; Carvalho, H. W. P.; Casapu, M.; Grunwaldt, J. D. HERFD-XANES and XES as complementary operando tools for monitoring the structure of Cubased zeolite catalysts during NOx-removal by ammonia SCR. J. Phys.: Conf. Ser. 2016, 712, 012071 .

(52) Borfecchia, E.; Lomachenko, K. A.; Giordanino, F.; Falsig, H.; Beato, P.; Soldatov, A. V.; Bordiga, S.; Lamberti, C. Revisiting the nature of $\mathrm{Cu}$ sites in the activated Cu-SSZ-13 catalyst for SCR reaction. Chem. Sci. 2015, 6, 548-563.

(53) Pappas, D. K.; Borfecchia, E.; Dyballa, M.; Lomachenko, K. A.; Martini, A.; Berlier, G.; Arstad, B.ør.; Lamberti, C.; Bordiga, S.; Olsbye, U.; Svelle, S.; Beato, P. Understanding and Optimizing the Performance of $\mathrm{Cu}$-FER for The Direct $\mathrm{CH} 4$ to $\mathrm{CH} 3 \mathrm{OH}$ Conversion. Chem CatChem 2019, 11, 621-627.

(54) Bauer, M. HERFD-XAS and valence-to-core-XES: new tools to push the limits in research with hard X-rays? Phys. Chem. Chem. Phys. 2014, 16, 13827-13837.

(55) Lafuerza, S.; Retegan, M.; Detlefs, B.; Chatterjee, R.; Yachandra, V.; Yano, J.; Glatzel, P. New reflections on hard X-ray photon-in/photon-out spectroscopy. Nanoscale 2020, 12, 1627016284.

(56) Palagin, D.; Knorpp, A. J.; Pinar, A. B.; Ranocchiari, M.; van Bokhoven, J. A. Assessing the relative stability of copper oxide clusters as active sites of a CuMOR zeolite for methane to methanol conversion: size matters? Nanoscale 2017, 9, 1144-1153.

(57) Kulkarni, A. R.; Zhao, Z.-J.; Siahrostami, S.; Nørskov, J. K.; Studt, F. Monocopper Active Site for Partial Methane Oxidation in Cu-Exchanged 8MR Zeolites. ACS Catal. 2016, 6, 6531-6536.

(58) Ravel, B.; Newville, M. ATHENA, ARTEMIS, HEPHAESTUS: data analysis for X-ray absorption spectroscopy using IFEFFIT. $J$. Synchrotron Radiat. 2005, 12, 537-541.

(59) Perdew, J. P.; Burke, K.; Ernzerhof, M. Generalized Gradient Approximation Made Simple. Phys. Rev. Lett. 1996, 77, 3865-3868.

(60) Kühne, T. D.; Iannuzzi, M.; Del Ben, M.; Rybkin, V. V.; Seewald, P.; Stein, F.; Hutter, J.; et al. CP2K: An electronic structure and molecular dynamics software package - Quickstep: Efficient and accurate electronic structure calculations. J. Chem. Phys. 2020, 152, 194103.

(61) VandeVondele, J.; Krack, M.; Mohamed, F.; Parrinello, M.; Chassaing, T.; Hutter, J. Quickstep: Fast and accurate density functional calculations using a mixed Gaussian and plane waves approach. Comput. Phys. Commun. 2005, 167, 103-128.

(62) Grimme, S.; Antony, J.; Ehrlich, S.; Krieg, H. A consistent and accurate $\mathrm{ab}$ initio parametrization of density functional dispersion correction (DFT-D) for the 94 elements H-Pu. J. Chem. Phys. 2010, $132,154104$.

(63) Goedecker, S.; Teter, M.; Hutter, J. Separable dual-space Gaussian pseudopotentials. Phys. Rev. B: Condens. Matter Mater. Phys. 1996, 54, 1703-1710.

(64) VandeVondele, J.; Hutter, J. Gaussian basis sets for accurate calculations on molecular systems in gas and condensed phases. J. Chem. Phys. 2007, 127, 114105.

(65) Ankudinov, A. L.; Ravel, B.; Rehr, J. J.; Conradson, S. D. Realspace multiple-scattering calculation and interpretation of $\mathrm{x}$-ray- 
absorption near-edge structure. Phys. Rev. B: Condens. Matter Mater. Phys. 1998, 58, 7565-7576.

(66) Valiev, M.; Bylaska, E.J.; Govind, N.; Kowalski, K.; Straatsma, T.P.; Van Dam, H.J.J.; Wang, D.; Nieplocha, J.; Apra, E.; Windus, T.L.; de Jong, W.A. NWChem: A comprehensive and scalable opensource solution for large scale molecular simulations. Comput. Phys. Commun. 2010, 181, 1477-1489.

(67) Lopata, K.; Van Kuiken, B. E.; Khalil, M.; Govind, N. LinearResponse and Real-Time Time-Dependent Density Functional Theory Studies of Core-Level Near-Edge X-Ray Absorption. J. Chem. Theory Comput. 2012, 8, 3284-3292.

(68) Henkelman, G.; Arnaldsson, A.; Jónsson, H. A fast and robust algorithm for Bader decomposition of charge density. Comput. Mater. Sci. 2006, 36, 354-360. 